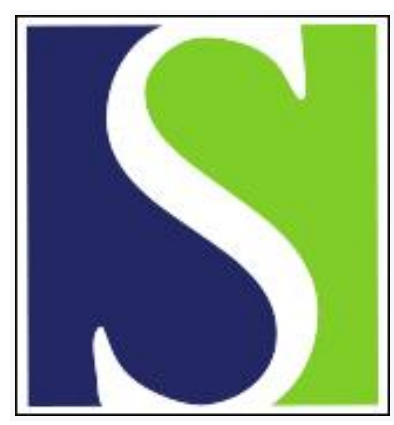

Scand J Work Environ Health 2001;27(3):157-160

https://doi.org/10.5271/sjweh.604

Issue date: Jun 2001

Work-related factors and mortality - what is the burden?

by Hernberg $\mathrm{S}$

Affiliation: Scandinavian Journal of Work Environment \& Health, Topeliuksenkatu 41 a A, FI-00250 Helsinki, Finland.

Refers to the following text of the Journal: 2001;27(3):161-213

The following article refers to this text: 2003;29(2):83-84

Key terms: editorial; mortality; work-related factor

This article in PubMed: www.ncbi.nlm.nih.gov/pubmed/11444412 


\section{Work-related factors and mortality — what is the burden?}

It has been known for centuries that certain specific occupational exposures, such as lead, asbestos, and silica, can cause fatal diseases. Work accidents have killed people from the beginning of our history. However, during the last few decades, work conditions, and even the nature of work, have changed drastically, at least in the developed world. The number of fatal work accidents has dropped, and most classical occupational diseases have decreased in both number and severity. The credit goes partly to improvements in occupational hygiene, partly to advances in production technology, and partly to completely new work conditions. For some health policy makers, this development has created the illusion that occupational medicine, as we used to define it, belongs to the past. However, even if some problems have been partially or completely solved, others have emerged. A vast number of epidemiologic studies has shown that many nonspecific conditions, such as several forms of cancer and cardiovascular disease, still may have a work-related etiology. "New" specific conditions, for example, many allergies, also indicate that the work environment still poses risks. Ergonomic and psychosocial stressors appear to cause ill health as well. If we scrutinize the work-related etiology of nonspecific diseases and apply good epidemiology and biostatistics, the lesson learned is that the work environment today, in spite of the decline of frank poisonings and other classical occupational diseases, is still full of health risks, many of which have been revealed rather recently.

As already mentioned, work-related risk factors, including potentially fatal ones, have been identified in numerous epidemiologic studies from around the world. Given the multitude of identified risk factors, the question arises of what the total burden of work-related etiology is in a country for causespecific and total mortality - and nonfatal forms of morbidity as well. Not many evidence-based attempts can be found in the literature for estimating the overall work-related fraction of mortality at a national level. This deficiency is understandable, since the task is heroic. Very often crucial data are lacking, either because work-related mortality has not been studied at all or because the quality of the studies available is poor. Nevertheless, national estimates are, under some circumstances, possible, even if vulnerable to gross errors, whereas global estimates are next to impossible, due to heterogeneous conditions across countries and lack of data from large parts of the world. National estimates are, of necessity, bound to time and place, because both exposure intensities and other work conditions vary from one country to another, and from one calendar period to another. Variations are large even within a country.

In this issue of the Scandinavian Journal of Work Environment \& Health, Nurminen \& Karjalainen have bravely entered a minefield by trying to assess the work-related share of mortality in Finland in 1996 (1). Although well aware that any such endeavor is inherently open to criticism, the editor decided to publish this "tête d'ouvre" not only to emphasize that work-related factors are still causing many deaths, maybe more than most of us think, but also to stimulate more similar research. In addition, this study will hopefully initiate a scholarly discussion for which space will be made available in coming issues of the Journal.

The main conclusion of Nurminen \& Karjalainen's study is that work-related factors accounted for about 1800 deaths in Finland in 1996; this figure stands for $7 \%$ of all deaths in the relevant age groups. This is a point estimate and should not be taken literally. It should also be remembered that the sum of etiologic fractions is greater, as a rule, than $100 \%$ (eg, $100 \%$ of avalanches are caused by snow, but 
steep slopes are also responsible for $100 \%$ of them, and weather conditions for an additional $50 \%$ or so). However, irrespective of whether the correct number of work-related deaths is 1000,1800 or 3000 , the message is that too many are due to work-related factors. At least in theory, "work-related" means "preventable". Although the causation of most deaths is a multifactorial matter, removing the work-related factor, if it is a so-called necessary factor, could "save lives". [Of course lives cannot be "saved", but death can be postponed and the cause of death can be altered (eg, old age instead of pleural mesothelioma at the age of 46).]

Another interesting conclusion is that "nonchemical" conditions are involved in several major causes of death, especially cardiovascular deaths. Work stress and shift work are the most widespread risk factors. This is an example of a problem area not influenced by improved occupational hygiene. On the contrary, it may be an adverse effect of the very modernization of worklife.

The literature related to work-related mortality is so vast that no conventional meta-analysis is feasible if the total burden of work-related deaths is to be assessed. Therefore, the authors have used another approach by focusing only on studies that, in their view, are valid and well documented. Their conclusions are based on a qualitative evaluation of these studies. Many studies, not cited in the reference list, have been disqualified. This is an approach that can be criticized since the procedure introduces subjectivity. However, contrary to what many scholars seem to believe, science is not objective but subjective, especially its interpretation. Why otherwise would the same available literature lead to parallel, conflicting "world views" on so many matters? And considering how many weak studies overflow the literature on occupational epidemiology, why let ten or so poor studies obscure the message brought forward by one or two good ones in a formal meta-analysis? [Disqualifying weak studies during the qualitative stage of a meta-analysis is also based on subjective judgment.] I do not believe that "objective" meta-analysis, while probably valid for clinical trials, is a good solution in occupational epidemiology, where the study designs are not uniform, the quality of studies varies, to say the least, and exposure conditions are different across almost all studies, if documented at all. The relative risks of the studies are consequently, frankly speaking, totally incomparable for the purposes of a meta-analysis. Of two unsatisfactory methods, I prefer educated and critical qualitative judgment, although I admit that a risk of bias is involved, especially if the criteria for inclusion are influenced by the study outcome.

Difficulties with defining exposure conditions in the population at large, however, also pose a problem for extrapolation. It is well known that exposure assessment is the Achilles heel of even the best of studies, not to speak of the average ones. This is especially true for exposures that have occurred decades ago - a common problem with cancer studies. So how should the relative risk of, say, 2 observed for a population in one study be extrapolated to other, unstudied populations in the same occupation or branch of industry? These groups may work in rather different (unmeasured) conditions. If the different studies on which the extrapolation is based show different relative risks (which may be due to different but poorly defined exposure conditions), how should the "correct" relative risk be chosen for extrapolation? What about studies on the same topic that show no excess relative risk? And where is the border between "exposed" and "unexposed", especially considering that people change employment? Although Nurminen \& Karjalainen have relied on a Finnish jobexposure matrix, the exposure assessment of the "exposed" population at large cannot be very exact. Hence the extrapolation becomes guesswork, although perhaps educated guesswork. That errors may level out is a weak defense. The problems are apparent, but who can provide a better alternative?

It is also a pity that most cohort studies on occupational mortality have used the general population as the reference category. The general population is far from a valid reference group. Therefore such "standardized mortality ratio studies" (SMR studies) are heavily biased, partly because of the socalled healthy worker effect. Much has been written about the healthy worker effect, but little has been 
done to remedy it (ie, to use better study designs). Generally speaking, the comparison bias caused by the healthy worker effect is said to be negative, but the matter is probably not that simple. The healthy worker effect is known to be different for different causes of death, smaller for cancer than for cardiovascular diseases, and so forth - but how much? The social class of a cohort also influences the healthy worker effect in the sense that higher categories show a stronger such effect than lower ones, for which the healthy worker effect may even be reversed if the follow-up is long enough. As long as the vast majority of the (cohort) literature is made up of SMR studies, anyone analyzing and summarizing their results, irrespective of method, is in great difficulty. Extrapolations multiply the (unknown) errors of individual studies.

Apart from the healthy worker effect, there are other problems involved in SMR studies. It is not feasible to measure and, consequently, control potential confounders, such as tobacco smoking or alcohol consumption, in the general population. Social factors are also beyond control, because the general population is a mix of all social strata, while the "exposed" cohorts usually represent only one stratum. It is well known that life-style is related to social class, and life-style factors, such as smoking and drinking, can often have more impact on mortality than work-related factors. Indirectly life-style and occupation are often interrelated, and their separation is usually not possible in a constellation in which the general population serves as the reference category. Cohort studies with valid ad hoc reference groups and well-designed case-referent studies are superior in this respect.

Many of the occupational hazards manifesting themselves as excess mortality have exerted their action years or decades earlier; hence many of the excess deaths occurring during a certain year do not automatically reflect present-day exposure conditions. Others, such as occupational accidents, mirror very recent conditions. The outcome (ie, work-related mortality) in a certain year is thus a mix of the effects of immediately acting and long-term risk factors. From the point of view of deeper analyses of causes and effects, cause-specific mortality gives more information on what preventive action should be taken than does total mortality, although the latter may provide a better summary figure of the magnitude of the problem. It should also be noted that mortality statistics only reflect the tip of the iceberg - nonfatal work-related conditions, such as musculoskeletal disorders, nonfatal accidents, hearing loss and dermatoses, would give the problem quite another dimension if included in the overall risk assessment. In fact, in a recent interview study comprising 31500 persons, Statistics Finland found by extrapolation that more than 1 million, or nearly half of the work force, thought that they suffered from some work-related disorder (2).

Some of the extrapolations in Nurminen \& Karjalainen's study are partly based on studies carried out in other countries. Provided the exposure assessments in these studies are reliable, their results can probably be generalized also to the Finnish population, especially if corrections are made for variations in exposure intensities across countries (a very difficult task). Likewise, many of the Finnish results probably also apply to some extent to other countries with similar work conditions. Even so, it may be hazardous to generalize Nurminen \& Karjalainen's results directly to other countries. But if some $7 \%$ of all deaths - give or take a few percent — indeed are work-related in a country with supposedly fairly good work conditions, one may really wonder how great this share is in less developed countries.

All in all, in spite of potential errors - which would affect all similar studies - Nurminen \& Karjalainen's results indicate that work-related morbidity, here measured as mortality, is a major problem and that strong preventive efforts are still needed. Occupational health care has thus a great challenge even today. Downsizing this sector, as has taken place in some countries, is not a wise solution. Controlling stress-related factors of different kinds, allergens, and passive tobacco smoking, especially, should receive more attention. Modern worklife is not yet safe, although the risks may differ from those of 50 years ago. Especially the ever-increasing mental demands put on qualified employees 
cause concern. Coping with these problems will need strong support from management, the continuous education and training of occupational health personnel, and the integration of psychosocial expertise into the health care team.

\section{References}

1. Nurminen M, Karjalainen A. Epidemiologic estimate of the proportion of fatalities related to occupational factors in Finland. Scand J Work Environ Health 2001; 27: 161-213.

2. Paananen S, editor. Työn vaarat: koetut työperäiset sairaudet, työtapaturmat ja työväkivaltatapaukset 1999. [Dangers at work: perceived occupational diseases, accidents and violence at work in 1999]. Helsinki: Statistics Finland, 2000. Työmarkkinat 2000:15. English summary.

Sven Hernberg, MD, Editor Emeritus

Scandinavian Journal of Work Environment \& Health 